\title{
High Levels of Glucose-6-Phosphatase Gene and Protein Expression Reflect an Adaptive Response in Proliferating Liver and Diabetes
}

\author{
Barbara A. Haber, ${ }^{\star 5}$ Simon Chin, ${ }^{\star 5}$ Emil Chuang, ${ }^{\star 5}$ Wieneke Buikhuisen, * Ali Naji," and Rebecca Taub** \\ *Department of Genetics, ${ }^{\ddagger}$ Howard Hughes Medical Institute, Division of Gastroenterology and Nutrition, ${ }^{8}$ Department of Pediatrics, \\ Children's Hospital of Philadelphia, "Department of Surgery, University of Pennsylvania School of Medicine, Philadelphia, Pennsylvania \\ 19104-6145
}

\begin{abstract}
The regenerating liver after partial hepatectomy is one of the few physiologic models of cellular proliferation in the adult animal. During hepatic regeneration, the animal is able to maintain metabolic homeostasis despite the acute loss of two thirds of hepatic tissue. In examining the molecular mechanisms regulating hepatic regeneration, we isolated novel immediate-early genes that are rapidly induced as the remnant liver undergoes the transition from its normal quiescent state into the G1 phase of the cell cycle. One of the most rapidly and highly induced genes which we initially termed RL-1, encodes rat glucose-6-phosphatase (rG6Pase). G6Pase mRNA peaks at $30 \mathrm{~min}$ and $36-48 \mathrm{~h}$ after hepatectomy correlating with the first and second rounds of cell division. This finding is compatible with studies that showed that G6Pase enzyme activity increases during liver regeneration. However, the increase in G6Pase mRNA is much more dramatic, indicating that it is a more sensitive indicator of this regulation. G6Pase gene expression peaks in the perinatal time period in the liver and remains elevated during the first month of life. The expression of the G6Pase gene is also dramatically elevated in BB diabetic rats, again higher than the enzyme elevation, and its relative induction after partial hepatectomy is blunted in these animals. Insulin treatment of partially hepatectomized diabetic animals downregulates the expression of G6Pase mRNA. Using specific antibodies against G6Pase, we detect a 36-kD G6Pase protein, and its level is elevated in regenerating and diabetic livers. The pattern of G6Pase mRNA expression appears to reflect similar changes in insulin and glucagon levels which accompany diabetes and hepatic proliferation. The elevation of G6Pase expression in these conditions is indicative of its importance as a regulator of glucose homeostasis in normal and abnormal physiologic states. (J. Clin. Invest. 1995. 95:832-841.) Key words: metabolism • liver regeneration • hepatectomy - molecular sequence data - fetal development
\end{abstract}

\section{Introduction}

The regenerating liver after partial hepatectomy is one of the few adult organs that demonstrates a physiologic growth re-

Address correspondence to Rebecca A. Taub, Howard Hughes Medical Institute, Department of Genetics, University of Pennsylvania, School of Medicine, Philadelphia, PA 19104-6145. Phone: 215-898-9131; FAX: 215-573-2195. 1994.

Received for publication 7 June 1994 and in revised form 6 October

J. Clin. Invest.

(C) The American Society for Clinical Investigation, Inc.

0021-9738/95/02/0832/10 \$2.00

Volume 95, February 1995, 832-841 sponse (1-3). As such it provides an intact animal model in which cellular proliferation can be studied. Within minutes after two thirds partial hepatectomy, the majority of cells in the remnant liver which are normally quiescent rapidly reenter the cell cycle accompanied by the induced expression of a large number of growth response genes. The onset of DNA synthesis occurs at $12-16 \mathrm{~h}$ after hepatectomy in hepatocytes with peak level at $24 \mathrm{~h}$, and the mass of the liver is restored within 7-10 d when proliferation ceases. A number of growth factors has been implicated as having a role in this process including HGF, TGF $\alpha$, insulin, glucagon, and others, but the exact mechanisms regulating this process are unknown. As the liver is a vital organ, it must maintain metabolic and synthetic homeostasis throughout the regenerative period. Studies have shown that there is an acute fall in insulin and an increase in glucagon levels immediately after hepatectomy both of which begin to renormalize within a few hours, thereby preventing the hypoglycemia which might accompany the loss of liver mass $(4,5)$. Previously, we and others (6-9) showed that phosphoenol pyruvate kinase (PEPCK $)^{1}$ and other genes involved in glucose homeostasis are rapidly up- or downregulated in the regenerating liver, thus allowing the remnant liver to maintain glucose balance.

To begin to define the molecular basis for liver regeneration, our laboratory first identified a large number of novel immediate-early genes that are induced in the remnant liver within minutes after partial hepatectomy (10). In total we have examined the expression of more than 70 immediate-early genes expressed in the regenerating liver. Of these, approximately one third show liver-restricted induction and are not induced in mitogen-stimulated cells such as $3 \mathrm{~T} 3$ fibroblasts $(10,11)$. One of these, $R L-1(10,12,13)$, showed a very high peak of expression within 30 min after hepatectomy and was expressed in a tissue-restricted fashion with highest levels in liver and kidney. As we were particularly interested in defining the liver-specific aspects of cell growth, we focused on the characterization of $R L-1$. After completing several studies, we found upon a repeat data bank search that $\mathrm{RL}-1$ is the rat homologue of the recently identified glucose-6-phosphatase (G6Pase) gene (14).

G6Pase is a key regulatory enzyme in glucose homeostasis, catalyzing the final step in gluconeogenesis and glycogenolysis (15). Decreased levels are found in two different diseases. In glycogen storage disease type 1, a mutated form of G6Pase is found (16). In tyrosinemia type 1 , toxic by-products secondary to a deficiency of fumaryl acetoactetate result in decreased expression of G6Pase. The mouse model for this form of tyrosinemia has demonstrated that the usual perinatal expression of G6Pase is blunted $(14,17)$. Purification of G6Pase was difficult because of its tight association with the endoplasmic reticulum

1. Abbreviations used in this paper: G6Pase, glucose-6-phosphatase IGFBP-1, insulin-like growth factor binding protein-1; PEPCK, phosphoenol pyruvate kinase; RT, reverse transcriptase. 

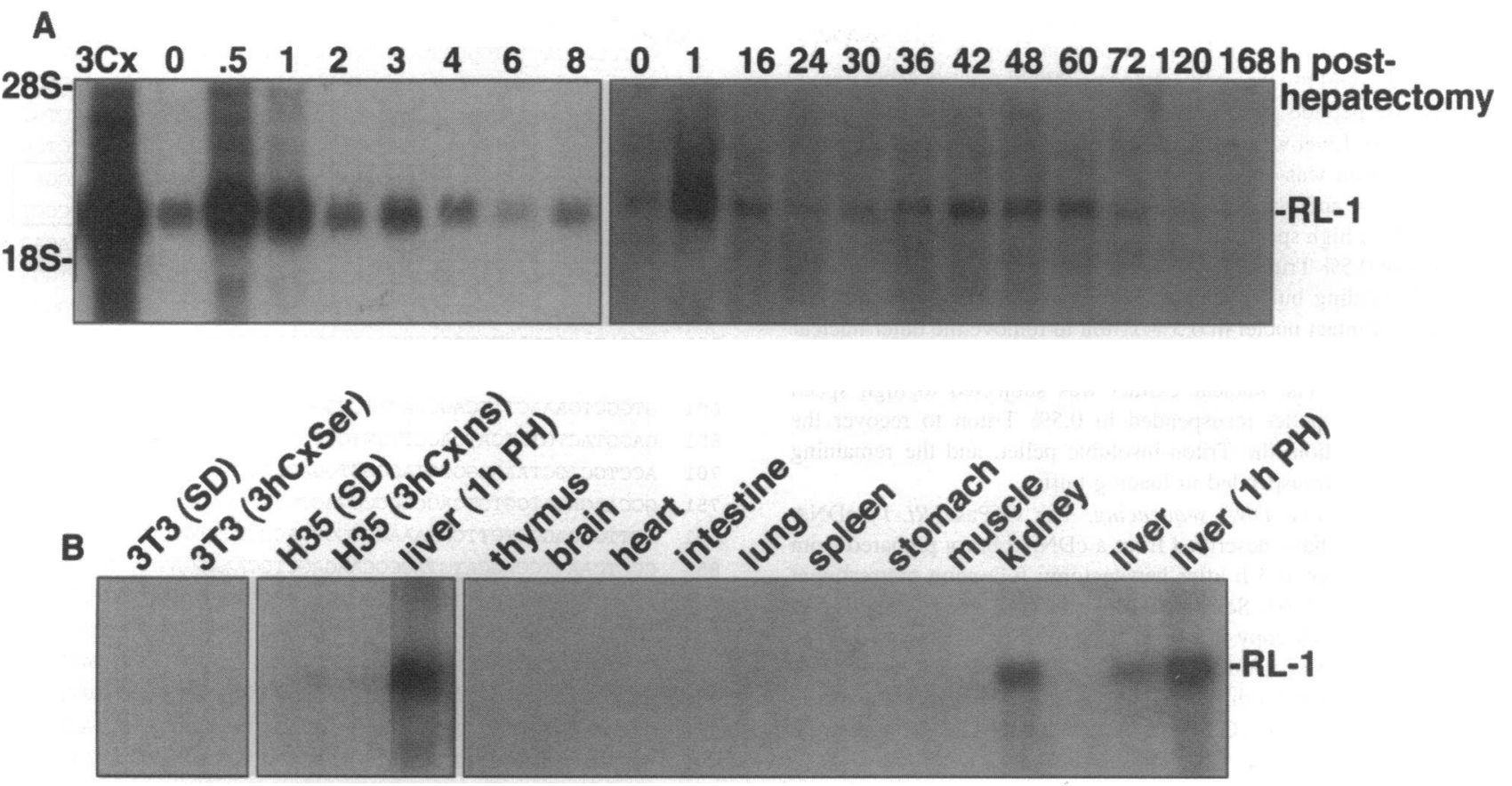

Figure 1. Expression of the $R L-1$ gene in regenerating liver and normal tissues. $(A)$ Northern blot probed with a ${ }^{32} \mathrm{P}-\mathrm{labeled} R L-1 \mathrm{cDNA} .10 \mu \mathrm{g}$ of each liver RNA sample was loaded per lane as confirmed by control probes and ethidium-stained ribosomal RNA bands. Number of hours after hepatectomy is indicated. $3 C x$ indicates pretreatment of the animal with cycloheximide followed by partial hepatectomy and collection of the RNA $3 \mathrm{~h}$ later. Left panel, short time course; right panel, long time course. $(B) R L-1$ 's expression is restricted to liver and kidney. Samples are $3 T 3$, Balbc/3T3 fibroblasts; SD, serum-deprived ( $48 \mathrm{~h}$ in $1 \%$ serum); or $3 \mathrm{hCxSer}$, treated with $10 \% \mathrm{FBS}$ for $3 \mathrm{~h}$ in the presence of cycloheximide; H35 cells, treated as in Methods by serum deprivation for $72 \mathrm{~h}(S D)$ or serum deprivation for $72 \mathrm{~h}$ followed by insulin in the presence of cycloheximide $(3 h C x I n s)$. Samples are from indicated adult rat tissue.

and nuclear membranes (18-21). Using enzymatic assays, G6Pase has commonly been used as a marker for hepatocytes. It is present in the periportal area in normal liver, but dispersed throughout the liver at $4 \mathrm{~h}$ after hepatectomy (22). Its expression in diabetics and its regulation by insulin are complex. G6Pase activity has been reported to be high in diabetic animals $(23-25)$, regardless of glycemia $(26,27)$, and its activity has been shown to be decreased by insulin and increased by glucagon (28). Here we examine the expression of the G6Pase gene in regeneration of the liver, fetal hepatic development, and diabetic animals. We find that the G6Pase gene is highly expressed under several experimental conditions which may reflect the basis of its regulation in different hormonal milieus. We show that G6Pase protein levels correlate with mRNA levels under these conditions, but that mRN.A levels change more dramatically. These expression patterns are indicative of the importance of G6Pase as a regulatory enzyme in glucose metabolism in physiologic and pathophysiologic conditions.

\section{Methods}

Animals and cell lines. H-35 cells were grown as described previously (29). After serum deprivation, cells were treated with various agents: insulin ( $10^{-8} \mathrm{M}$; Sigma Immunochemicals, St. Louis, MO), serum (20\% FBS), and cycloheximide ( $10 \mu \mathrm{g} / \mathrm{ml}$; Sigma Immunochemicals ). Balb/ 3T3 cells were grown and induced with serum (20\% FBS) with or without cycloheximide $(10 \mu \mathrm{g} / \mathrm{ml})$ as described (10). For regenerating liver, Fischer rats (160-200 g; Bantin and Kingman, Inc., Fremont, CA) were ether anesthetized and subjected to midventral laparotomy with $\sim 70 \%$ liver resection (left lateral and median lobes) (30). For cycloheximide-treated samples, rats were treated with $50 \mathrm{mg} / \mathrm{kg}$ cyclo- heximide (5\% solution in PBS) intraperitoneally 15 min before surgery (10). RNA was prepared in $4 \mathrm{M}$ guanidine thiocyanate buffer and RNA prepared as described (31).

Diabetic BB rats (300-400 g), aged 3-5 mo, were maintained on $2 \mathrm{U}$ of sc lente (long-acting) insulin daily. Insulin was witheld on the day of surgery when, after ether anesthesia, $70 \%$ liver resection was performed as described above. Rats were subsequently killed at different time points, and total liver RNA was prepared. Blood glucose (Accuchek III; Boehringer Mannheim, Indianapolis, IN) and serum insulin levels (RIA assay; Diabetes Center Core, University of Pennsylvania Medical School) were measured preoperatively and at the time of killing.

For fetal liver samples, timed pregnant Fischer female rats were purchased from Charles River Laboratories (Wilmington, MA), and embryos were harvested on the indicated days. Total RNA was extracted from the fetal livers after homogenization in guanidine thiocyanate. Each RNA sample represents more than one fetal liver.

Northern blots. Northern blot analyses and labeling of recombinant $R L-1 / G 6$ Pase plasmids have been described (10). Hybridization buffer consisted of $10 \%$ dextran sulfate, $40 \%$ formamide, $0.6 \mathrm{M} \mathrm{NaCl} / 0.06$ M Na Citrate, $7 \mathrm{mM}$ Tris ( $\mathrm{pH} 7.6), 0.8 \times$ Denhardt's solution, and $0.002 \%$ heat-denatured, sonicated salmon sperm DNA. Northern blots were hybridized at $42^{\circ} \mathrm{C}$ for $16 \mathrm{~h}$ and washed $2 \times 30 \mathrm{~min}$ at $60^{\circ} \mathrm{C}$ in $0.015 \mathrm{M} \mathrm{NaCl} / 0.0015 \mathrm{M} \mathrm{Na}$ citrate/0.1\% SDS before exposure to film (31).

Antibodies and immunoblots. Anti-polyclonal rG6Pase antibodies were prepared by Cocalico Biologicals (Reamstown, PA) against bacterially expressed purified denatured rG6Pase peptide (amino acids 238311 ). The peptide was expressed as we have described previously using a PET expression vector system (32) after cloning a PCR-generated fragment in front of the polyhistidine region. The sequence was confirmed. Immunoblots were performed as we have described using a 1:1,000 dilution of affinity-purified anti-G6Pase antisera followed by a 
1:10,000 dilution of goat anti-rabbit sera and the chemiluminescence detection system (Amersham Corp., Arlington Heights, IL) (33). Affinity-purified $\alpha$-G6Pase was prepared on an affigel column using immobilized G6Pase peptide and showed enhanced anti-G6Pase activity.

Cell extracts. Liver was extracted and fractionated as described (34). Nuclei preparation was verified by microscopy, as we have done previously $(34,35)$, and was $99 \%$ pure. Cytoplasmic material was further fractionated by a high speed $(100,000 \mathrm{~g})$ spin, followed by resuspension of the pellet in $0.5 \%$ Triton, and resuspension of the final Triton-insoluble pellet in loading buffer. Nuclear material was further fractionated by treatment of intact nuclei in $0.5 \%$ Triton to remove the outer nuclear membrane, lysis of nuclei by dounce homogenization, and recovery of nuclear extract. The nuclear extract was subjected to high speed centrifugation, the pellet resuspended in $0.5 \%$ Triton to recover the Triton-soluble fraction, the Triton-insoluble pellet, and the remaining insoluble material resuspended in loading buffer.

$c D N A$ cloning and DNA sequencing. The G6Pase $(R L-1)$ cDNA was isolated as we have described from a cDNA library prepared from regenerating rat liver at $3 \mathrm{~h}$ after hepatectomy following pretreatment with cycloheximide (10). Several different cDNAs were isolated. The near full-length cDNA copy was verified by primer extension analysis. DNA sequencing was performed bidirectionally using the oligonucleotide primer extension modification of Sanger dideoxy methodology (36). Intelligenetics and GCG DNA software and a BLAST search were used in sequence analyses.

Reverse transcriptase PCR. RNA previously extracted from liver at various time points after partial hepatectomy was used for the reverse transcriptase (RT) reaction. Each RT reaction was performed in a 20 $\mu 1$ volume buffer $(0.05 \mathrm{M}$ Tris $/ \mathrm{HCl}, \mathrm{pH} 8.3,0.075 \mathrm{M} \mathrm{KCl}, 3 \mathrm{mM}$ $\mathrm{MgCl}_{2}, 10 \mathrm{mM}$ DTT), consisting of $2 \mu \mathrm{g}$ of RNA, 8 pmol of $3^{\prime}$ primer (CGAAAGATAGCGAGAGTAGA), $0.01 \mathrm{mM}$ DTT, $1 \mathrm{mM}$ of each dNTP and $200 \mathrm{U}$ of Moloney murine leukemia virus RT (GIBCO BRL, Grand Island, NY). This was incubated for $90 \mathrm{~min}$ at $37^{\circ} \mathrm{C}$ followed by $5 \mathrm{~min}$ at $65^{\circ} \mathrm{C}$. The primers used for the PCR reaction include the $5^{\prime}$ primer (ACTGGTTCAACCTCGTCTT), and the $3^{\prime}$ primer was the same as that used for the RT reactions. The $5^{\prime}$ and $3^{\prime}$ primers were end-labeled with T4 polynucleotide kinase (New England Biolabs, Beverly, MA) and $0.01 \mathrm{mCi}$ of $\left[{ }^{32} \mathrm{P}\right] \gamma \mathrm{dATP}$ at $37^{\circ} \mathrm{C}$ for $30 \mathrm{~min}$. The PCR reactions were performed in $40-\mu 1$ volumes of Vent buffer $(10 \mathrm{mM}$ $\mathrm{KCl}, 20 \mathrm{mM}$ Tris/ $\mathrm{HCl}, \mathrm{pH} 8.8,10 \mathrm{mM}\left(\mathrm{NH}_{4}\right)_{2} \mathrm{SO}_{4}, 2 \mathrm{mM} \mathrm{MgSO}_{4}$, and $0.1 \%$ Triton $\mathrm{X}-100$ ) containing $2 \mu \mathrm{l}$ of DNA from the RT reaction, 30 pmol of each primer, with $20 \%$ of each primer as end-labeled primer, $2.5 \mathrm{mM}$ of each dNTP, and $1 \mathrm{U}$ Vent (New England Biolabs). The alternate form of $R L-1$ cDNA without the exon was used as a control. The PCR reaction gave a predicted fragment size of 209 and $99 \mathrm{bp}$ for the full length and exon 2 minus G6Pase mRNA forms, respectively. The products were electrophoresed on a $5 \%$ denaturing polyacrylamide gel relative to molecular size standards.

G6Pase enzymatic assays. Enzymatic activity of G6Pase in liver tissue was detected by a modified technique of Teutsch et al. (37). 10$\mu \mathrm{m}$ frozen section slides were exposed to G6Pase substrate for $30 \mathrm{~min}$ at $37^{\circ} \mathrm{C}$ and subsequently washed briefly in $0.22 \%$ ammonium sulfide before fixation with acetone/methanol (1:1). Slides were then counterstained lightly with hematoxylin.

G6Pase activity of subcellular fractions of liver tissue was assayed by incubating dilutions of the fractions in G6Pase substrate mixture at $37^{\circ} \mathrm{C}$ for $60 \mathrm{~min}(18)$. After stopping the reaction in $10 \%$ trichloroacetic acid, samples were centrifuged at $3,500 \mathrm{rpm}$ at $4^{\circ} \mathrm{C}$ for $20 \mathrm{~min}$ and an aliquot of the supernatant incubated with $10 \%$ ascorbic acid/ $0.42 \%$ ammonium molybdate $(1: 6)$ at $42^{\circ} \mathrm{C}$ for $20 \mathrm{~min}$ before reading at $\mathrm{OD}$ $820 \mathrm{~nm}$. Specific activity was calculated after standardization with appropriate dilutions of potassium phosphate and determination of the protein concentrations of the fractions by the BCA (Pierce, Rockford, IL) protein assay method.

Immunohistochemistry. Immunohistochemistry was performed essentially as has been described $(33,38) .10-\mu$ m frozen tissue sections were fixed in ice cold methanol for $10 \mathrm{~min}$. The Vectastain Elite $A B C$ (Vector Labs, Inc., Burlingame, CA) avidin biotin horseradish peroxidase detection system was used according to the manufacturer's instruc-

1 GCCAGCTTCCTGAGGTACCAAGGAGGAAGGATGGAGGAAAGAATGAACGT 51 GCTCCACGACTTTGGGATCCAGTCGACTCGCTACCTCCAAGTGAATTACG 101 AAGACTCCCAGGACTGGTTTGTCTTGGTGTCTGTGATCGCTGACCTCAGG 151 AACGCCTTCTATGTCCTCTTTCCCATCTGGTTCCACATTCAAGAGACTGT 201 GGGCATCAATCTCCTCTGGGTGGCAGTGGTTGGAGACTGGTTCAACCTCG 251 TCTTTAAGT GATTCTTTTTGGACAGCGCCCGTATTGGTGGGTCCTGGAC 301 ACTGACTATTACAGCAACAGCTCCGTGCCTCTGATAAAACAGTTCCCCGT 351 CACCTGTGAGACTGGACCAGGGAGTCCCTCGGGCCATGCCATGGGCACAG 401 CAGGTGTATACTACGTTATGGTTACTTCTACTCTCGCTATCTTTCGTGGA 451 AAGAAAAAGTCAACGTATGGATTCCGGTGCTTGAATGTCGTCTTGTGGTT 501 GGGATACTGGGCTGTGCAGCTGAACGTCTGTCTGTCCCGGATCTACCTTG CGGCTCACTTTCCCCATCAGGTGGTGGCTGGAGTCTTGTCAGGCATTGCT GTGGCTGAAACTTTCAGCCACATCCGGGGCATCTACAATGCCAGCCTCCA GAGGTACTGTCTCATCACCTTCTTCCTGTTTGGTTTCGCACTTGGATTTT ACCTGCTGCTAAAGGGGCTAGGGGTGGACCTCCTGTGGACTTTGGAGAAG GCCAAGAGATGGTGTGAGCGCCCCGAGTGGGTCCACCTTGACACTACACC СTTTGCCAGCCTCTTCAAAAACCTGGGGACCCTCTTGGGGTTGGGGCTGG CCCTCAACTCCAGCATGTACCGCAAGAGCTGCAAAGGAGAACTGCGCAAG TCGCTCCCATTCCGTTTGGCCTGCATCGTGGCCTCCTTGGGCCTGCTGCA TCTCTTTGACTCGCTGAAGCCCCCGTCCCAGATTGAGTCGATCTTCTACA TCTTGTCTTTCTGCAAGAGTGCGACCGTCCCCTTTGCATCTGTCAGTCTT ATCCCCTACTGCCTAGCCCGGCTCCTGGGACAGACACACAAGAAGTCTTT GTAAAGCGTTึAaGTCTCTGACACAAGTCAGCGGCCGTGAAAGGACTAGG AGCAACCCAAGCCTTGTGCAACCCAGTGTGGGGCCAGAGGTGTTCACAGC CACCCTGGTAGCCCTGTCTTTCTTTGCCATCGTAACCAAAAAGGTGAATT TTTAAAAGCTAACAGGGCTGTTTGAGGAAAGCGTGAATGCTGGAAGATGT TTCCCTGATGAATCACTTCCGGTCTCCTGTCCGACACAGAAGAGAAAGCC CAGACTAGAGATCCTGACAGAATGCTCTCACTGTGCAGAATCCTCCAGGC CGAGGGTAAAAGAAAAGAGCGTTGTGCATTTGCTAGGAAGAGAAGGAAGG ATCGGGAGGAGGGGGAGTGTTTGGTGGATTGAGCAAACCATATGCAAGCC ATGTCTACCCGGCTTCAGTTATGCCTGGGTCTTTAGATATGTAGGACACT CTCAATAATGATAGACCAGCCCGTGTAATGAGTAGCCAGTTAGAGGCGAT CATTCTGCTCCCAGATTTTTCTCTACTGTACATGAAAGTCACACCGTGTG CTTGTATTCCTGAATGGTAATGGTGACTGTCACTCAGGAACCACCACCTT CTCTGTGACACCACAGCTTTGCCTCCTCGGCCCAGGTCTGCGTGCCATAG GACTCATCACTGCTTCCCTGACCACGCTGCTGGACCCTGCATTGCTGAAC CCCATGCTGCTGGACCCTGTGGTGTACGGTGGGCAATTGTTTGCTGGTGC TTTTGTAGGGTTAAGTTAAACTCTGAGATCTTGGGCAAAACGGCAAGGGG AGAGTCAGGATTCCTCTCTCCAAAGGTCACTCCGAAGTTACTTTTGATTC CTGGAGCAGAAATGACTCCTTCCTCTAGCCCAAGCCAGCCAAGAACTCAT TCTTAGAGGCAAAGCAGCCCAAGCCCGACTGTGCCTGTCCTCCAGCCTGG GCTGGTTTTGCAGAGTGTGTCTTCAAGAAGAAAAAATGGTAAAGCTATTT ATTCAAAATGCTTGTTTTTTGCTATGAATGATGCCTGTGTTTCCACCCAC GCCAAGCACTTGTTCCTATTGTCTTGATAAGAAACTACATGTGTGCAGTA

Figure 2. Sequence of rat G6Pase cDNA. Accession number L37333. The boxed area represents the region deleted from one cDNA clone and corresponds to exon 2 of the mouse cDNA (14). The translation initiation site and poly $\mathrm{A}$ addition signal are underlined and an asterisk indicates the position of the stop codon.

tions with these modifications. After the blocking step in 3\% goat serum in PBS, pH 7.3, avidin and biotin blocking steps were performed using the avidin biotin blocking kit (Vector Labs, Inc.). Primary antibody was diluted 1:500 in 3\% goat serum in PBS, and tissue sections were incubated for $40 \mathrm{~min}$ at room temperature in a humidified chamber. After the secondary antibody incubation step, the sections were incubated with $0.3 \%$ hydrogen peroxide in methanol for $30 \mathrm{~min}$ to quench endogenous peroxidase activity. The slides were then dehydrated in graded alcohols and xylene and mounted with permount.

\section{Results}

$R L-1$ is induced as a liver-restricted immediate-early gene in regenerating liver. $R L-1$ represents an abundant induced gene 

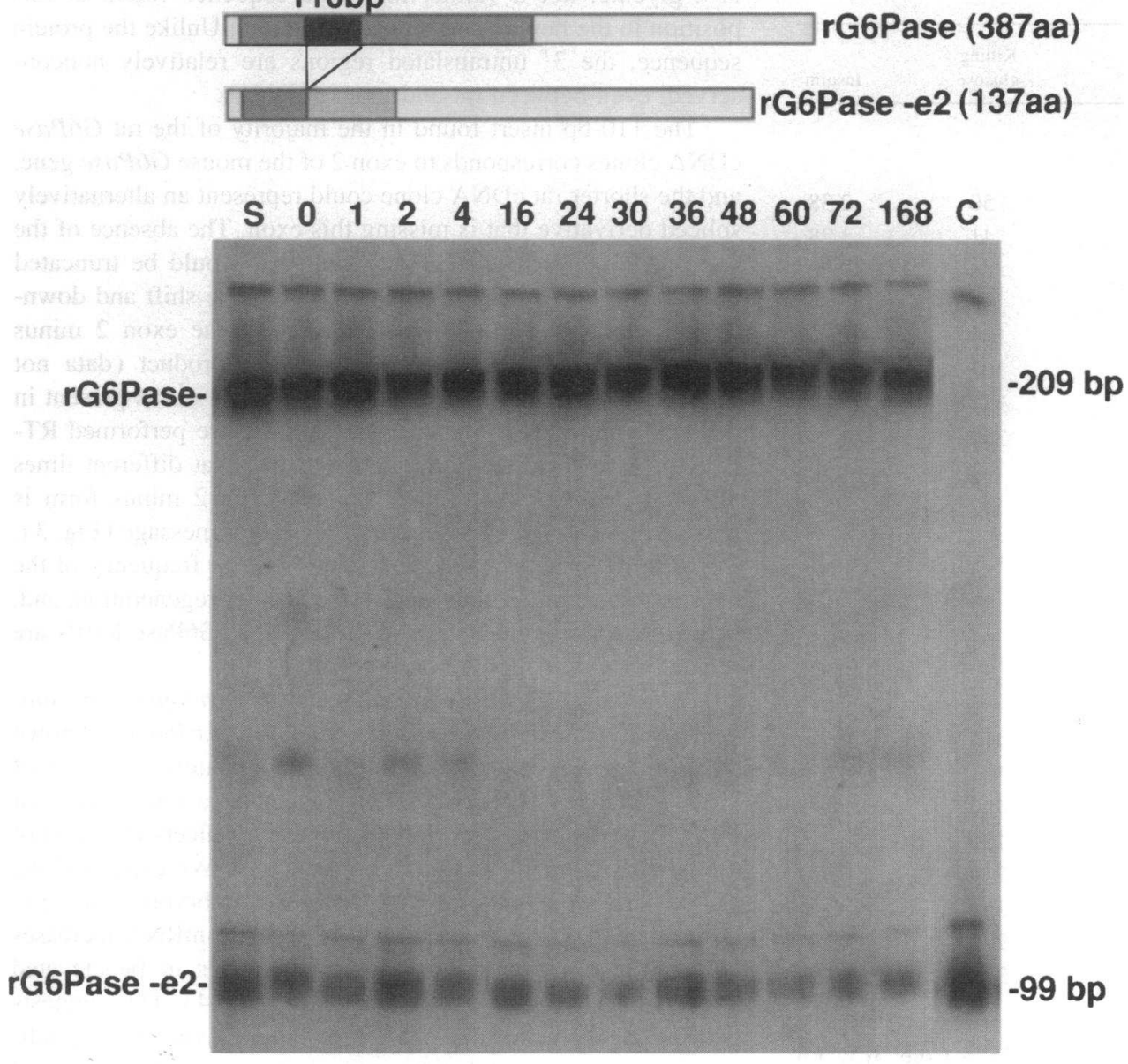

Figure 3. Two spliced forms of the G6Pase mRNA in rat liver. RT-PCR of RNA from indicated time after hepatectomy. S, sham surgery at $1 \mathrm{~h} ; \mathrm{C}$, control using e2 minus cDNA.

in the regenerating liver (Fig. 1), but unlike most immediateearly genes it shows some expression in normal liver cells. Nonetheless it is induced more than 25 -fold by $30 \mathrm{~min}$ after hepatectomy. Its identification as an immediate-early gene is confirmed by its superinduction in the presence of cycloheximide treatment ( $3 \mathrm{Cx}$ ). $R L-1$ shows peak expression during the first $\mathrm{G} 1$ phase of regeneration and a second peak that coincides with the second G1 phase in hepatocytes (Fig. $1 A$ ) (39). Unlike most immediate-early genes, $R L-1$ is not induced in insulintreated H35 cells or 3T3 cell fibroblasts (Fig. $1 B$ ). H35 cells are a minimal deviation hepatoma cell line that shows normal regulation of most immediate-early genes $(6,7,40)$. Interest- ingly, we had shown that two genes, insulin-like growth factor binding protein-1 (IGFBP-1) and PEPCK, are induced as immediate-early genes in regenerating liver and downregulated in insulin-treated $\mathrm{H} 35$ cells $(6,7,40)$. These genes are known to be downregulated at the transcriptional level by insulin. However, in serum-deprived $\mathrm{H} 35$ cells, as the level of $R L-1$ mRNA is barely detectable, insulin treatment has an imperceptible effect. Unlike almost all other immediate-early genes, $R L-1$ is highly induced by sham surgery up to $50 \%$ of the level induced by partial hepatectomy (10). Although $R L-1$ mRNA is present primarily in liver and kidney (Fig. $1 B$ ), in previous studies we found that $R L-1 \mathrm{mRNA}$ is present in both hepatocytes and

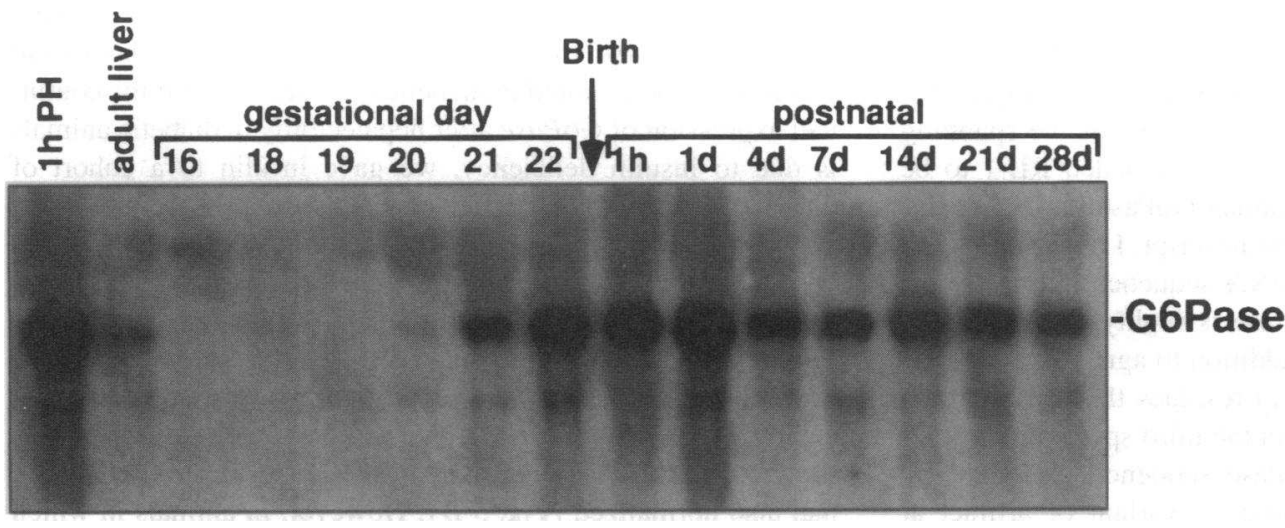

Figure 4. G6Pase mRNA expression in the perinatal and newborn periods. Northern blot probed as described for Fig. 1. Gestational day and days after birth are indicated. 
Table I. Glucose and Insulin Values of Diabetic and Normal Animals

\begin{tabular}{|c|c|c|c|c|}
\hline & Animal & $\begin{array}{l}\text { Preop } \\
\text { glucose* }\end{array}$ & $\begin{array}{l}\text { Killing } \\
\text { glucose }\end{array}$ & Insulin \\
\hline \multicolumn{5}{|l|}{ Normal } \\
\hline $3 C x$ & 11 & & & \\
\hline 0 & 57 & & 50 & 2.38 \\
\hline 1 & 142 & 102 & 41 & 1.28 \\
\hline 8 & 63 & 107 & 88 & 0.92 \\
\hline \multicolumn{5}{|c|}{ Diabetic } \\
\hline $3 C x$ & 7 & & 180 & \\
\hline 0 & 19 & & 301 & 0.45 \\
\hline 1 & 39 & 342 & 351 & 0.30 \\
\hline 8 & 51 & 370 & 309 & 0.55 \\
\hline $8+i$ & 25 & 355 & 61 & 1.37 \\
\hline $8+i$ & 15 & 338 & 37 & 3.08 \\
\hline \multicolumn{5}{|c|}{ Normal } \\
\hline 0 & 57 & & 50 & 2.38 \\
\hline 0 & 66 & & 89 & 5.79 \\
\hline 1 & 142 & 102 & 41 & 1.29 \\
\hline 1 & 67 & 95 & 79 & 0.82 \\
\hline \multicolumn{5}{|c|}{ Diabetic } \\
\hline 0 & 109 & & 414 & 0.71 \\
\hline 0 & 19 & & 301 & 0.45 \\
\hline 0 & 9 & & 450 & 2.94 \\
\hline 0 & 20 & & 180 & \\
\hline 1 & 13 & 190 & 240 & 0.86 \\
\hline 1 & 39 & 342 & 351 & 0.35 \\
\hline 1 & 158 & 305 & 280 & 2.10 \\
\hline 1 & 149 & 244 & 307 & 1.70 \\
\hline
\end{tabular}

* Assay by Chemstrip; ${ }^{\ddagger}$ Radioimmunoassay, Diabetes Core. $3 C x, 3 \mathrm{~h}$ after animal treatment with cycloheximide and partial hepatectomy.

nonparenchymal liver cells (11). This is unlike other liverspecific genes such as PEPCK whose expression is restricted to the hepatocyte fraction. As the nonparenchymal cells are mixed populations, it is not clear which cells in the nonparenchymal population express $R L-1$. Thus, $R L-1$ was of particular interest because it is a liver-restricted immediate-early gene, and we targeted it for further analyses.

RL-1 encodes rat G6Pase, a highly conserved hydrophobic protein. $R L-1$ cDNA clones isolated from the regenerating liver library represented two classes. Several contain a 110-bp insert which is missing from a single cDNA clone. DNA sequence analysis revealed that the shorter clone contains an interrupted open reading frame and could only encode 137-aa protein, whereas the longer clone contained an open reading frame of 357 amino acids. Initially the $R L-1$ sequence was unique ( 12 , 13 ) and only notable for several potential membrane spanning segments, but a recent data bank search revealed RL-1 to be the rat homologue of mouse and human G6Pase (14) (Fig. 2). At the time of submission of this manuscript, Lange et al. (41) presented a partial rat G6Pase cDNA sequence and a protein alignment that indicates that G6Pase is highly conserved between human, rat, and mouse. In addition to agreeing with their comments, we note that amino acid residues that are common between two species are different in the third species indicating divergent evolution. The rat G6Pase sequence presented by Lange et al. (41) appears to contain a variant or artifact at amino acid 118, because our sequence indicates that this residue is a glycine, not a valine, the same sequence found at this position in the human and mouse sequences. Unlike the protein sequence, the $3^{\prime}$ untranslated regions are relatively nonconserved, even between rat and mouse cDNAs.

The 110-bp insert found in the majority of the rat G6Pase cDNA clones corresponds to exon 2 of the mouse G6Pase gene, and the shorter rat cDNA clone could represent an alternatively spliced derivative that is missing this exon. The absence of the exon 2 sequence results in a protein that would be truncated after 137 amino acids due to the initial frame shift and downstream stop codon. In vitro translation of the exon 2 minus synthetic mRNA did not yield a protein product (data not shown). To determine whether this splice variant is present in cells or is an artifact of the cDNA library, we performed RTPCR of RNA samples prepared from livers at different times after hepatectomy. We found that the exon 2 minus form is present at $\sim 20 \%$ the frequency of the larger message (Fig. 3 ). There is no consistent variation in the relative frequency of the two messages during the time course of liver regeneration, and, therefore, there is no reason to suspect that G6Pase levels are regulated by splicing after hepatectomy.

G6Pase mRNA levels are high in the developing and diabetic liver, and insulin downregulates its expression. It is known that G6Pase levels are low until approximately the time of birth when they increase (14). Thus, it is a late marker of differentiation in the developing liver and reflects the need of the newborn animal for glucose production. We examined the profile of expression of G6Pase mRNA in embryonic and newborn rats and found that the level of G6Pase mRNA increases abruptly at embryonic day 21 and continues to be elevated above adult levels until 4 wk after birth (Fig. 4). This suggests that the mechanism by which G6Pase gene expression is activated in the perinatal time period may involve hormonal changes that occur just before birth when insulin levels fall and glucagon levels increase (42).

G6Pase is involved in glucose homeostasis, and in the diabetic animal its basal level is elevated $(25,26)$. We examined alterations of G6Pase gene expression after partial hepatectomy in $\mathrm{BB}$ diabetic rats as compared with normal animals. The metabolic profile of the animals studied is provided in Table I. We found that G6Pase mRNA is consistently elevated in diabetic animals and that after hepatectomy the relative induction of G6Pase mRNA is blunted in the diabetic animals (Fig. $5 \mathrm{~A}$ ). After normalization to the control gene, ATP synthase, the relative induction in the diabetic animals was 1.4 as compared with $\sim 25-30$-fold for the normal animals. The level of G6Pase mRNA at $1 \mathrm{~h}$ after hepatectomy in the normal and diabetic animals was approximately equal because of the elevation in the diabetic animals before hepatectomy. At $8 \mathrm{~h}$ after hepatectomy, the G6Pase level has normalized in normal animals but continues to be elevated in diabetics. To determine if the continued expression of G6Pase after hepatectomy in diabetic animals is due to insulin deficiency, we gave insulin to a cohort of diabetic animals at $4 \mathrm{~h}$ after hepatectomy and obtained liver and serum samples at $8 \mathrm{~h}$ after hepatectomy. These studies were complicated by the fact that the pretreatment level of G6Pase mRNA could not be measured in any individual animal, and thus several animals were studied to provide sufficient data to draw conclusions. In diabetic animals in which glucose, insulin, and PEPCK mRNA levels had normalized by $8 \mathrm{~h}$ after hepatectomy following insulin treatment, the level of G6Pase mRNA had also normalized (Fig. $5 B$ ). However, in animals in which 

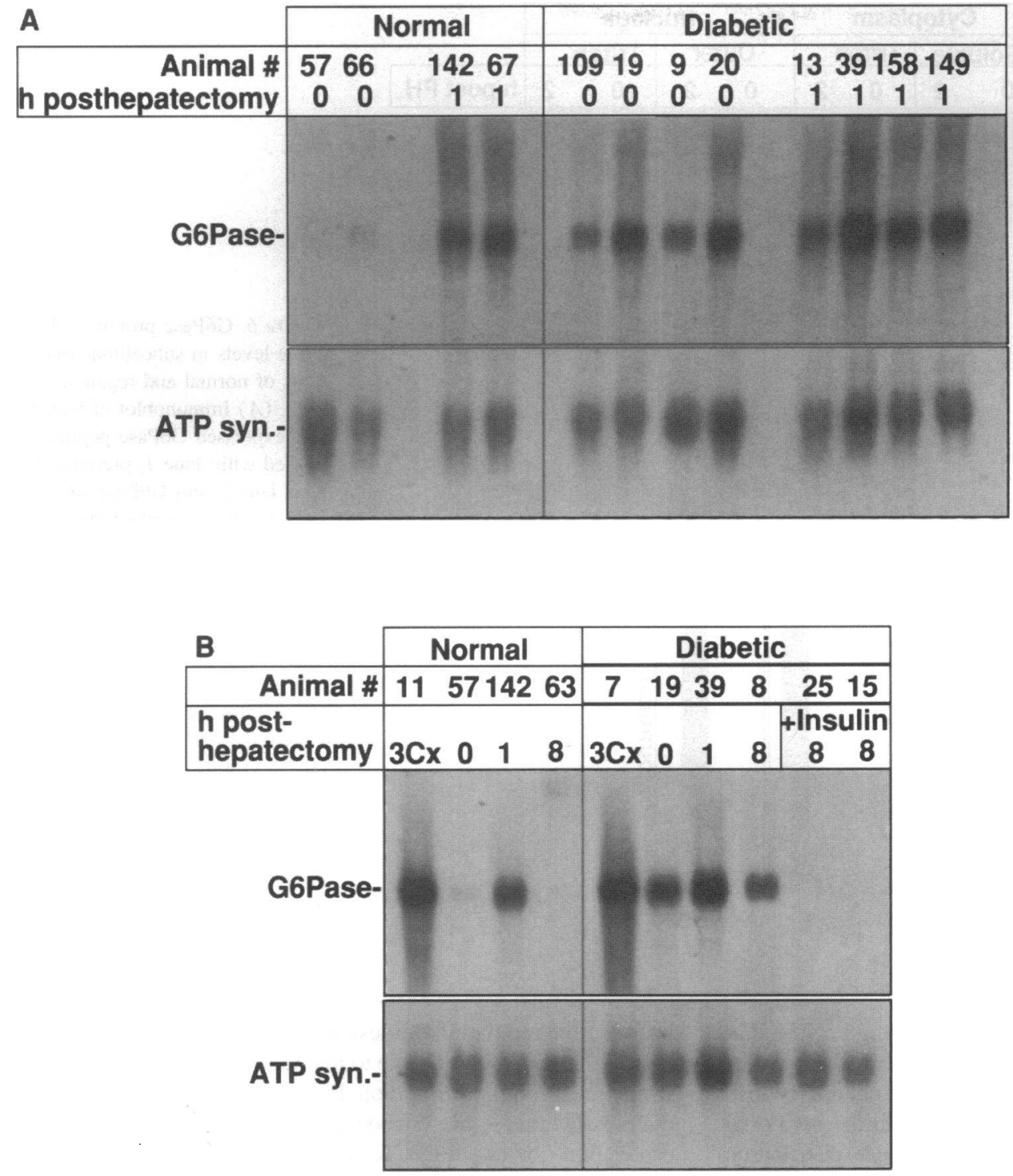

Figure 5. G6Pase mRNA levels in diabetic animals, and the regulation of the gene after hepatectomy. (A) Expression of G6Pase mRNA in two different normal and four different diabetic animal livers at 0 and $1 \mathrm{~h}$ after hepatectomy. (B) Expression of G6Pase mRNA up to $8 \mathrm{~h}$ after hepatectomy in normal and diabetic animals in the absence or presence of insulin treatment. $0.5 \mathrm{U}$ regular insulin was given at $4 \mathrm{~h}$ after hepatectomy to the treated animals. glucose, insulin, and the level of expression of PEPCK (Chin, S., unpublished data) were not corrected by insulin treatment, G6Pase mRNA also remained uncorrected.

The highest specific activity of G6Pase protein and enzymatic activity is found in the nuclear membrane, and the level is elevated in diabetes and regenerating liver. Based on the G6Pase gene expression, we predicted that G6Pase protein and enzymatic activity should be high in regenerating and diabetic liver. It was important to document a correlation between protein and mRNA levels using antibody and enzymatic studies. We raised specific antisera to a nonhydrophobic region of the protein expressed in bacteria. As shown (Fig. $6 \mathrm{~A}$ ), these antisera are specific for the peptide, and affinity purification demonstrates enhanced activity. In total cellular immunoblots, G6Pase protein was not detected above the background levels, so subcellular fractionation was performed. G6Pase is a marker for cellular microsomes, but when nuclear/cytoplasmic fractionation is performed much of the activity is associated with nuclear membranes (21). This is not surprising since the endoplasmic reticulum forms a continuum with nuclear membranes. On immunoblots, a single band with a molecular mass of $36 \mathrm{kD}$ is de- tected in the nuclear membrane fraction of the cell. The level of this protein is fourfold higher in the sample prepared at $2 \mathrm{~h}$ after hepatectomy than in normal liver (Fig. $6 \mathrm{~B}$, right). This protein band correlates with the known cellular localization of G6Pase, its molecular mass, and its induction profile in the regenerating liver. To assess the correlation between protein and enzymatic levels, enzymatic assays were performed on the same fractions. The Triton-soluble nuclear fraction had the highest specific activity. However, as nuclear membranes represent only $3 \%$ of total cellular protein, total enzyme activity was highest in the Triton-soluble cytoplasmic fraction. G6Pase was not detectable by immunoblot in this fraction because G6Pase represents a smaller percentage of the cytosolic membrane proteins. The relative induction of G6Pase is most apparent in the nuclear membrane fraction (Fig. $6 C$, fraction $E$ ) where it is induced by more than fivefold, similar to the induction observed on immunoblot.

We also analyzed the tissue distribution of G6Pase by enzymatic and immunohistochemistry on tissue sections obtained from regenerating and diabetic livers (Fig. 7). In the normal and regenerating liver, enzymatic activity is periportal, with an 
A

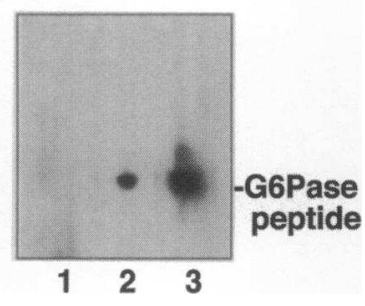

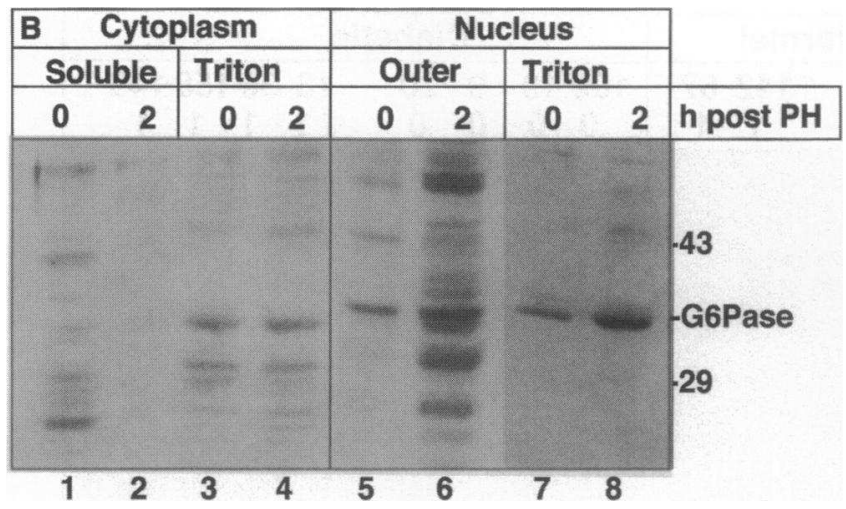

\section{C}

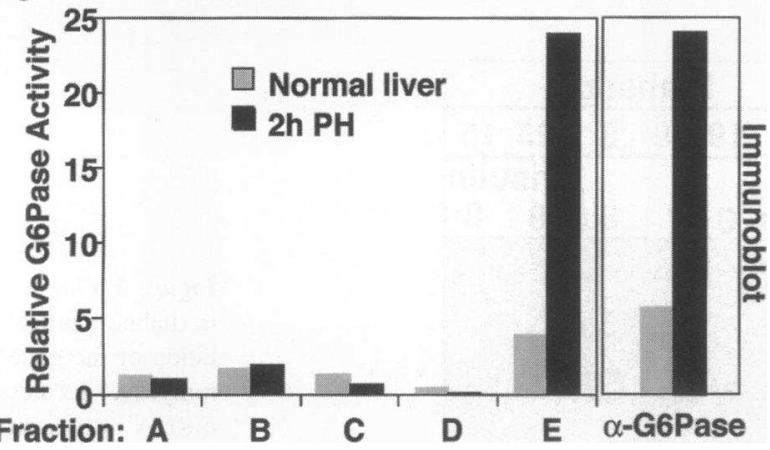

Figure 6. G6Pase protein and enzyme levels in subcellular fractions of normal and regenerating liver. ( $A$ ) Immunoblot of bacterially expressed G6Pase peptide blotted with: lane 1 , preimmune sera; lane 2, anti-G6Pase antisera; lane 3, affinity-purified antiG6Pase antisera. ( $B$ ) Immunoblot of cytoplasmic and nuclear fractions from normal and 2-h posthepatectomy liver. Fractions were made as described in Methods including soluble cytoplasmic extract, Triton-soluble cytoplasmic material, outer nuclear membrane ( $0.5 \%$ Triton), and Triton-soluble nuclear material. $(C)$ Enzyme activity of fractions: $A$, soluble cytoplasmic extract; $B$, cytoplasmic membranes; $C$, external nuclear membrane; $D$, soluble nuclear extract; and $E$, nuclear membranes. increase in the demarcation in the regenerating liver. The diabetic liver has a diffuse and dramatic increase in the level of G6Pase, and much of the periportal staining pattern is lost. Antibody studies show an increase in G6Pase in the periportal areas of the posthepatectomy liver and a diffuse distribution pattern of protein in the diabetic liver. Quantitation of G6Pase was not possible on the tissue sections because glycogen deposition in the diabetic livers affected the appearance of the staining of these cells. At the cellular level, most of the staining appears to be perinuclear. The normal rat liver shows a low level of staining, also with a diffuse distribution pattern.

\section{Discussion}

During liver regeneration, the remnant liver must maintain the ability to regulate serum glucose levels. Immediately after hepatectomy, the portal vein insulin level rapidly falls as the glucagon level increases dramatically $(4,5)$. Changes in hormone levels allow normal serum glucose to remain stable despite the absence of two thirds of the liver. We have seen that several liver-specific immediate-early genes are either known or postulated to be involved in metabolic control. Understanding the basis for the regulation of these genes in liver regeneration may indicate how the liver is able to maintain metabolic homeostasis while undergoing proliferation. Examples of upregulated immediate-early genes that encode proteins important for glucose production include PEPCK, potentially IGFBP-1, and now G6Pase (6-10). Decreased expression of genes encoding Lpyruvate kinase, glucokinase, and 6-phosphofructo-2-kinase/ fructose-2,6-biphosphatase, which oppose gluconeogenesis, occurs rapidly after hepatectomy (8). The change in expression of these genes is important in controlling metabolism during liver regeneration. Likewise, in the perinatal time period, the level of G6Pase must increase near the time of birth in rodents to help insure that appropriate levels of glucose are produced. At the time of birth, insulin levels fall acutely and glucagon levels are elevated (42). The G6Pase gene is induced near the time of birth and its expression remains elevated during the first month of life in the rodent, a time of rapid growth. The absence of this induction is associated with mortality in the mouse tyrosinemia model. We have also found that a similar set of genes including PEPCK, IGFBP-1, and G6Pase mRNA is induced to some degree after sham surgery when most immediate-early genes are not (10). In sham surgery, the levels of insulin and

Figure 7. G6Pase enzyme histochemistry and immunohistochemistry of regenerating and diabetic livers. Enzymatic activity of frozen sections assayed in parallel from $(A)$ normal and 2-h posthepatectomy livers and $(B)$ normal and diabetic livers. Identical exposure time and a magnification of 10. Immunohistochemistry using affinity-purified antibody diluted 1:500 of $(i)$ normal, (ii) diabetic, and (iii) 2-h posthepatectomy livers. Identical exposure time and a magnification of 10 . (iv) 2-h posthepatectomy liver depicted at a magnification of 40. 
A

Normal

$2 \mathrm{~h}$ posthepatectomy

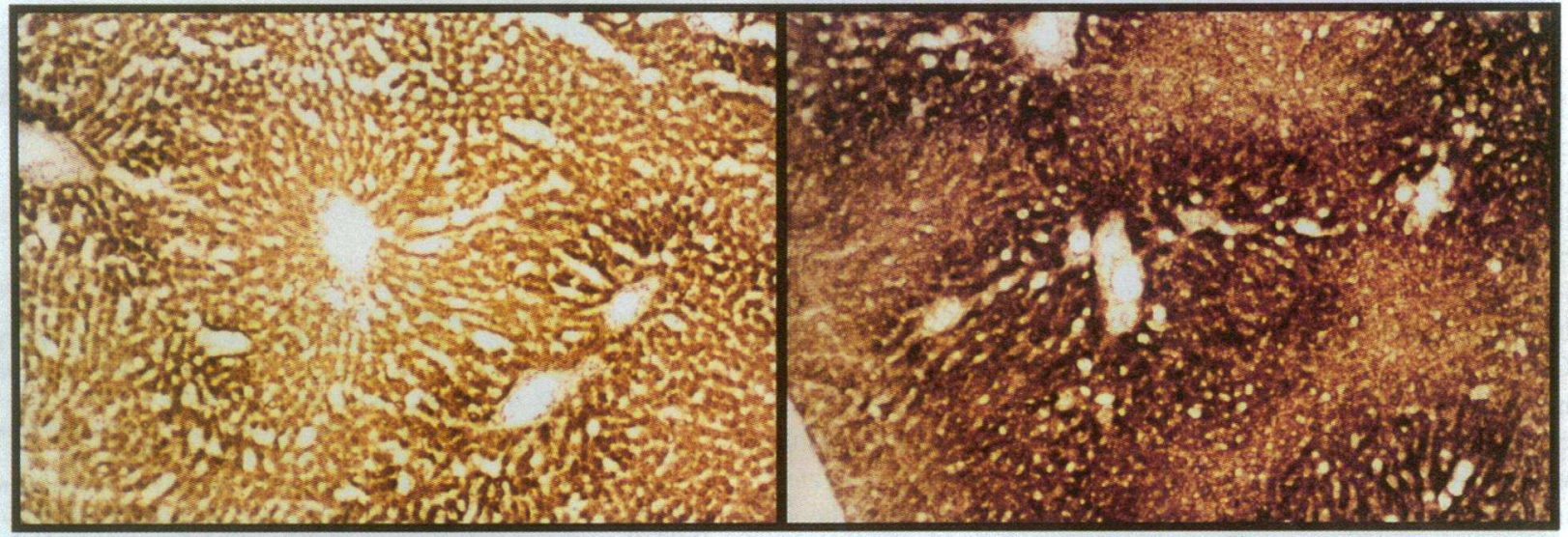

B Normal

Diabetic
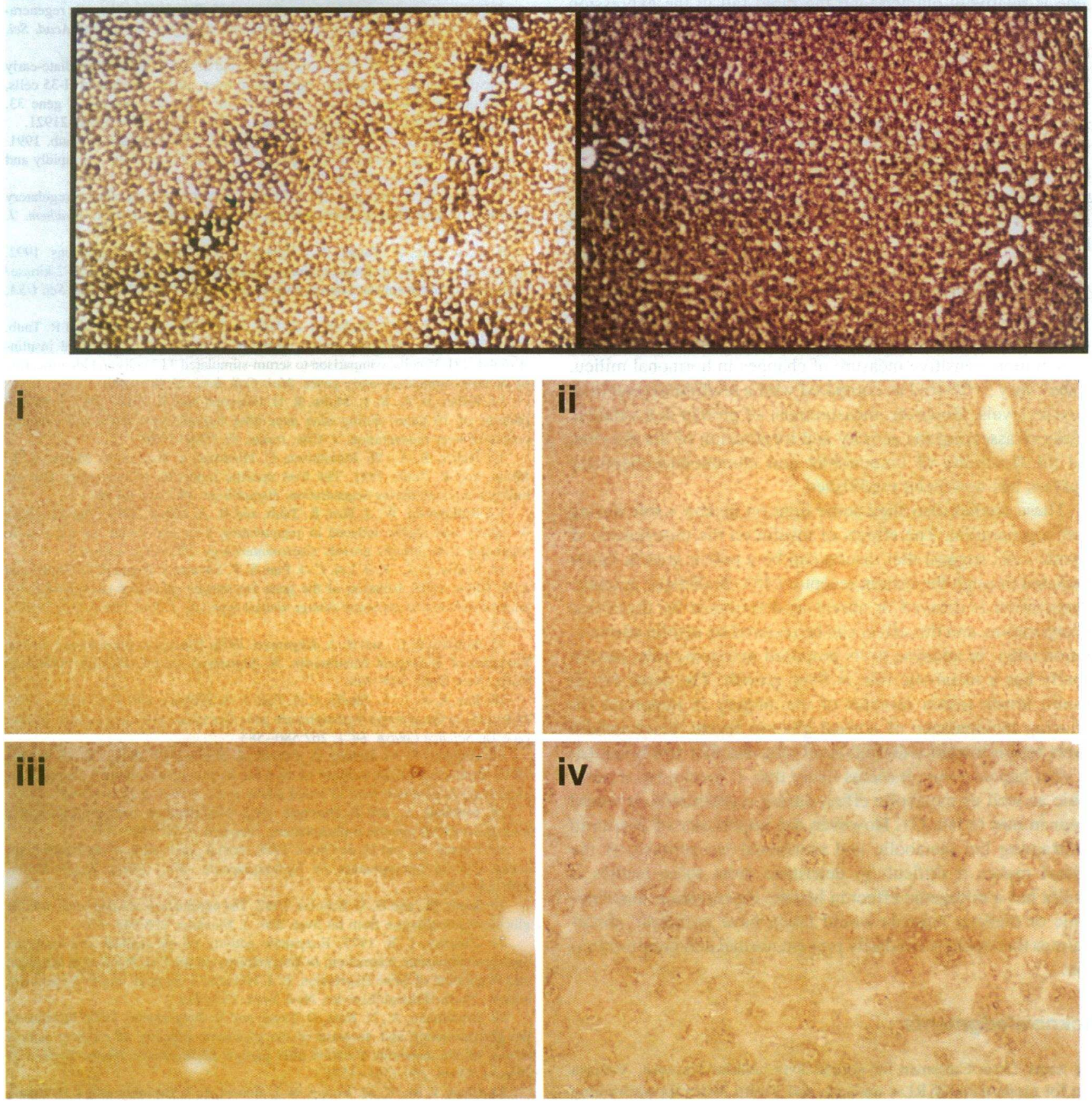
glucagon change in the same direction but to a lesser extent than after partial hepatectomy $(4,5)$. These hormonal changes may contribute to this upregulation.

Likewise, an increased glucagon to insulin ratio is seen in diabetes (43). Increased hepatic glucose production is the major cause of fasting hyperglycemia in all forms of diabetes. Diabetes increases the level of G6Pase activity in the liver while decreasing glucokinase resulting in a net increase in glucose production by the liver. Euglycemic clamp studies suggest that G6Pase levels are downregulated at least in part by the direct effect of insulin (26). Studies in FAO rat hepatoma cells suggest that G6Pase mRNA is induced by dexamethasone, dominantly downregulated by insulin, and modulated upwards in the presence of cAMP (glucagon mediator) (41). Our studies are compatible with these findings. Hepatic G6Pase mRNA is grossly elevated in all of the diabetic animals we have tested. After partial hepatectomy in these diabetic animals, the normal induction of this gene is relatively blunted, and the rapid fall in the expression of this gene by $8 \mathrm{~h}$ after hepatectomy is abolished. Insulin treatment can normalize the expression of the G6Pase gene in the posthepatectomy time period. Euglycemic clamp studies in diabetic animals will help establish if G6Pase mRNA levels can be corrected after insulin treatment when no surgery has been performed. PEPCK and IGFBP-1 are known to be controlled at the level of transcription by insulin (downregulation), glucagon/cAMP (upregulation), and glucocorticoids (upregulation). The expression patterns of the G6Pase gene predict that it may be similarly regulated $(10,33,44)$.

Our studies provide initial evidence that the levels of G6Pase protein and enzyme activity closely follow the mRNA levels in the various physiologic and pathophysiologic conditions we have studied. G6Pase mRNA levels appear to provide a much more sensitive measure of changes in hormonal milieu, as they vary $>20$-fold as compared with a fewfold in protein or enzyme levels. However, measurement of protein is a valuable means of assessing the activity and localization of the enzyme, and the feasibility of immunoblot and immunohistochemistry analyses has now been established.

These studies also shed some light on insulin's role during liver regeneration. The effects of insulin on the mitogenesis of hepatic cells suggest that insulin can be a potent growth factor mediated through the insulin receptor (45). In diabetic animals, regeneration is delayed or absent as determined by thymidine incorporation, and this effect can be restored by insulin administration (46). In addition to its proposed mitogenic role, insulin clearly has a metabolic role in liver growth. The acute fall in insulin levels within minutes of the surgery is important for allowing maintenance of normal glucose levels. Since insulin levels return toward a normal level after the first few hours (4, 5) after hepatectomy, it seems likely that, if insulin has a mitogenic as well as metabolic effect during regeneration, it would occur in mid to late G1. However, the importance of insulin in maintaining the metabolic and nutritional homeostasis of the animal makes it difficult to determine from these studies if insulin has a mitogenic effect in hepatic regeneration. Insulinopenic or diabetic animals would likely have metabolic abnormalities that could secondarily prevent normal cellular proliferation.

\section{Acknowledgments}

We thank Drew Cressman for normal liver cellular fractions, Victoria Lee for preparation of RL-1 antisera, and Vashti Miles for performing immunoblots against bacterially expressed peptide and for taking care of diabetic animals.

This work was supported in part by the Juvenile Diabetes Foundation (R. Taub), National Institutes of Health grant DK 01905 (B. A. Haber), Juvenile Diabetes Foundation (A. Naji), and the American Liver Foundation (S. Chin).

\section{References}

1. Fausto, N., and J. E. Mead. 1989. Regulation of liver growth: protooncogenes and transforming growth factors. Lab. Invest. 60:4-13.

2. Fausto, N., and E. M. Webber. 1994. Liver regeneration. In The Liver: Biology and Pathobiology. I. M. Arias, J. L. Boyer, N. Fausto, W. B. Jacoby, D. Schachter, and D. A. Shafritz, editors. Raven Press, New York. 1059-1084.

3. Michalopoulos, G. K. 1990. Liver regeneration: molecular mechanisms of growth control. FASEB (Fed. Am. Soc. Exp. Biol.) J. 4:176-187.

4. Bucher, N. L. R., J. A. McGowan, and U. Patel. 1978. Hormonal regulation of liver growth. In Cell Reproduction: In Honor of Daniel Mazia. E. R. Dirksen, D. M. Prescott, and C. F. Fox, editors. ICN-UCLA Symposia on Molecular and Cellular Biology. 661-670.

5. Bucher, N. L. R., and M. N. Swaffield. 1975. Regulation of hepatic regeneration in rats by synergistic action of insulin and glucagon. Proc. Natl. Acad. Sci. USA. 72:1157-1160.

6. Mohn, K. L., T. M. Laz, A. E. Melby, and R. Taub. 1990. Immediate-early gene expression differs between regeneration liver, insulin-stimulated H-35 cells, and mitogen-stimulated 3T3 cells: liver specific induction patterns of gene 33, PEPCK, and the jun, fos and egr families. J. Biol. Chem. 265:21914-21921.

7. Mohn, K. L., A. E. Melby, D. S. Tewari, T. M. Laz, and R. Taub. 1991. The gene encoding rat insulin like growth factor-binding protein 1 is rapidly and highly induced in regenerating liver. Mol. Cell. Biol. 11:1393-1401.

8. Rosa, J. L., R. Bartrons, and A. Tauler. 1992. Gene expression of regulatory enzymes of glycolysis/gluconeogenesis in regenerating rat liver. Biochem. J. 287:113-116.

9. Rosa, J. L., A. Tauler, A. J. Lange, S. J. Pilkis, and R. Bartrons. 1992. Transcriptional and posttranscriptional regulation of 6-phosphofructo-2-kinase/ fructose-2,6-bisphosphatase during liver regeneration. Proc. Natl. Acad. Sci. USA. 89:3746-3750.

10. Mohn, K. L., T. M. Laz, J.-C. Hsu, A. E. Melby, R. Bravo, and R. Taub. 1991. The immediate-early growth response in regenerating liver and insulinstimulated $\mathrm{H}-35$ cells: comparison to serum-stimulated 3T3 cells and identification of 41 novel immediate-early genes. Mol. Cell. Biol. 11:381-390.

11. Haber, B. A., K. L. Mohn, R. H. Diamond, and R. Taub. 1993. Induction patterns of 70 genes during nine days after hepatectomy define the temporal course of liver regeneration. J. Clin. Invest. 91:1319-1326.

12. Haber, B. A., W. Buikhuisen, C. Hindman, J. Hsu, A. E. Melby, K. L. Mohn, and R. Taub. 1991. The liver specific induction of two genes that are highly expressed during regeneration. Hepatology. 14:110a. (Abstr.)

13. Buikhuisen, W., J. Hsu, R. Taub, and B. A. Haber. 1992. The RL1 gene is rapidly and highly induced in regenerating liver and could have a role in regulating liver-specific growth. Gastroenterology. 102:A918. (Abstr.)

14. Shelly, L. L., K.-J. Lei, C.-J. Pan, S. F. Sakata, S. Ruppert, G. Shutz, and J. Y. Chou. 1993. Isolation of the gene for murine glucose-6-phosphatase, the enzyme deficient in glycogen storage disease type 1A. J. Biol. Chem. 268:2148221485

15. Nordlie, R. C., and R. A. Jorgenson. 1976. Glucose-6-phosphatase. In The Enzymes of Biological Membranes. A. Martonosi, editor. Plenum Publishing Corp., New York. 349-399.

16. Lei, K.-J., L. L. Shelly, C.-J. Pan, J. B. Sidbury, and J. Y. Chou. 1993. Mutations in the glucose-6-phosphatase gene that cause glycogen storage disease type 1a. Science (Wash. DC). 262:580-583.

17. Ruppert, S., G. Kelsey, A. Schedl, E. Schmid, E. Thies, and G. Schütz. 1992. Deficiency of an enzyme of tyrosine metabolism underlies altered gene expression in newborn liver of lethal albino mice. Genes \& Dev. 6:1430-1443.

18. Burchell, A., and B. Burchell. 1982. Identification and purification of a liver microsomal glucose 6-phosphatase. Biochem. J. 205:567-573.

19. Rymsa, B., and H. de Groot. 1988. Partial purification of rat liver microsomal glucose-6-phosphatase on hydroxylapatite. Biol. Chem. Hoppe-Seyler. 369:115-121.

20. Speth, M., and H.-U. Schulze. 1992. The purification of a detergent-soluble glucose-6-phosphatase from rat liver. Eur. J. Biochem. 208:643-650.

21. Zbarsky, I. B. 1975. Enzymatic activity of the nuclear envelope and nuclear-cytoplasmic interaction. In Biochemistry of the Cell Nucleus Mechanism and Regulation of Gene Expression. E. J. Hidvegi, J. Sümegi, and P. Venetianer, editors. North-Holland/Elsevier, New York. 213-218.

22. Brinkmann, A., N. Katz, D. Sasse, and K. Jungermann. 1978. Increase of the gluconeogenic and decrease of the glycolytic capacity of rat liver with a change of the metabolic zonation after partical hepatectomy. Hoppe-Seyler's $\mathrm{Z}$. Physiol. Chem. 359:1561-1571.

23. Chan, T. M., K. M. Young, N. J. Hutson, F. T. Brumley, and J. H. Exton. 
1975. Hepatic metabolism of genetically diabetic $(d b / d b)$ mice. I. Carbohydrate metabolism. Am. J. Physiol. 229:1702-1712.

24. Gardner, L. B., Z. Liu, and E. J. Barrett. 1993. The role of glucose-6phosphatase in the action of insulin on hepatic glucose production in the rat. Diabetes. 42:1614-1620.

25. Miethke, H., B. Wittig, A. Nath, S. Zierz, and K. Jungermann. 1985. Metabolic zonation in liver of diabetic rats. Biol. Chem. Hoppe-Seyler. 366:493501.

26. Barzilai, N., and L. Rossetti. 1993. Role of glucokinase and glucose-6phosphatase in the acute and chronic regulation of hepatic glucose fluxes by insulin. J. Biol. Chem. 268:25019-25025.

27. Lavoie, L., D. Dimitrakoudis, A. Maretet, B. Annabi, A. Klip, M. Vranic and G. van de Werve. 1993. Opposite effects of hyperglycemia and insulin deficiency on liver glycogen synthase phosphatase activity in the diabetic rat. Diabetes. 42:363-366.

28. Christ, B., I. Probst, and K. Jungermann. 1986. Antagonistic regulation of the glucose/glucose 6-phosphate cycle by insulin and glucagon in cultured hepatocytes. Biochem. J. 238:185-191.

29. Taub, R. A. Roy, R. Dieter, and J. Koontz. 1987. Insulin as a growth factor in rat hepatoma cells: stimulation of protooncogene expression. J. Biol. Chem. 262:10893-10897.

30. Higgins, G. M., and R. M. Anderson. 1931. Experimental pathology of the liver. I. Restoration of the liver of the white rat following partial surgical removal. Arch. Pathol. 12:186-202.

31. Sambrook, J., E. F. Fritsch, and T. Maniatis. 1989. Molecular Cloning A Laboratory Manual. Cold Spring Harbor Laboratory, Cold Spring Harbor, NY.

32. Rosenberg, A. H., B. N. Lade, D. S. Chui, S. W. Lin, J. J. Dunn, and F. W. Studier. 1987. Vectors for selective expression of cloned DNAs by T7 RNA polymerase. Gene (Amst.). 56:125-135.

33. Lee, J., L. Greenbaum, B. A. Haber, D. Nagle, V. Lee, V. Miles, K. L. Mohn, M. Bucan, and R. Taub. 1994. Structure and localization of the IGFBP-1 gene and its expression during liver regeneration. Hepatology. 19:656-665.

34. Diamond, R. H., D. E. Cressman, T. M. Laz, C. S. Abrams, and R. Taub.
1994. PRL-1, a unique nuclear protein Tyr-phosphatase, affects cell growth. Mol. Cell. Biol. 14:3752-3762.

35. Kuret, J., H. Bell, and P. Cohen. 1986. Identification of high levels of protein phosphatase-1 in rat liver nuclei. FEBS (Fed. Eur. Biochem. Soc.) Lett. 203:197-202.

36. Sanger, F., S. Nicklen, and A. R. Coulson. 1977. DNA sequencing with chain terminating inhibitors. Proc. Natl. Acad. Sci. USA. 74:5463-5467.

37. Teutsch, H. F. 1978. Improved method for the histochemical demonstration of glucose-6-phosphatase activity. Histochemistry. 57:107-117.

38. Harlow, E., and D. Lane. 1988. Antibodies: A Laboratory Manual. Cold Spring Harbor, Cold Spring Harbor, NY.

39. Grisham, J. W. 1962. A morphologic study of deoxyrobonucleic acid synthesis and cell proliferation in regenerating rat liver: autoradiography with thymidine-H. Cancer Res. 22:842-849.

40. Diamond, R. H., K. Du, V. M. Lee, K. L. Mohn, B. A. Haber, D. S. Tewari, and R. Taub. 1993. Novel delayed-early and highly insulin-induced growth response genes. J. Biol. Chem. 268:15185-15192.

41. Lange, A. J., D. Argaud, M. R. El-Maghrabi, P. Wansong, S. R. Maitra, and S. J. Pilkis. 1994. Isolation of a cDNA for the catalytic subunit of rat liver glucose-6-phosphatase: regulation of gene expression in FAO hepatoma cells by insulin, dexamethasone, and cAMP. Biochem. Biophys. Res. Commun. 201:302309.

42. Iritani, N., H. Fukuda, and Y. Matsumura. 1993. Lipogenic enzyme gene expression in rat liver during development after birth. J. Biochem. 113:519-525.

43. Unger, R. H., and L. Orci. 1994. "Glucagon" in Joslin's Diabetes Mellitus.

C. R. Kahn and G. C. Weir, editors. Lea \& Febiger, Malvern, PA. 163-176.

44. O'Brien, R. M., and D. K. Granner. 1991. Regulation of gene expression by insulin. Biochem. J. 278:609-619.

45. Taub, R., K. L. Mohn, R. H. Diamond, K. Du, and B. A. Haber. 1994 Molecular aspects of insulin regulated hepatic growth. In Molecular Biology of Diabetes, Part 2. B. Drazin and D. LeRoith editors. Humana Press, Totowa, NJ.

46. Barra, R., and J. C. Hall. 1977. Liver regeneration in normal and alloxaninduced diabetic rats. J. Exp. Zool. 201:93-100. 